\title{
Carrying out Collaborative Innovation to Promote Innovation and Service Ability of Local Colleges and Universities
}

\author{
Shuangshuang LI, Xiong LI, Yunyun ZHOU, Yihong HU, Wenxin JIN, Chenzhong JIN* \\ Hunan Provincial Collaborative Innovation Center for Field Weeds Control \\ Hunan University of Humanities, Science and Technology \\ Loudi, 417000, China \\ *Corresponding author, e-mail: 532479626@qq.com
}

\begin{abstract}
Based on the elaboration of basic connotation for collaborative innovation of local colleges and universities, the paper analyzes the dilemmas that local colleges and universities faced in the collaborative innovation environment, indicates that collaborative innovation is the best effective approach for the promotion of scientific and technological innovation and service ability of local colleges and universities, and meanwhile, it also suggests strengthening the consciousness of collaborative innovation, building the platform for collaborative innovation, and exploring the mechanism of collaborative innovation so as to provide reference for the promotion of scientific and technological innovation and service ability of local colleges and universities.
\end{abstract}

Keywords—collaborative innovation; local colleges and universities; scientific and technological ability; local service ability; promotion approach

\section{INTRODUCTION}

At present, with the rapid development of science and economy, local colleges and universities should carefully inspect the current situation and problems of scientific and technological innovation and service demands, actively explore new approaches and modes for the promotion of scientific and technological innovation and local service ability, which are not only beneficial to the comprehensive promotion of scientific and technological innovation and service ability of local colleges and universities, but also to the deep implementation of the strategy of rejuvenating the country through science and education, and the rapid advance of innovation-oriented national construction.

\section{CONNOTATION OF COLLABORATIVE INNOVATION}

Based on the guidance of great demands of the national social economic development and the combination of own talented persons and scientific research advantages, collaborative innovation of colleges and universities refers to creative activities of breakthroughs in scientific researches, talents cultivation and scientific achievements transformation made by universities cooperating with other universities, research institutions, industries and enterprises, local government or even some relevant foreign organizations. Not only is the collaborative innovation of colleges and universities different from traditional industry-universityresearch cooperation, but it has a fundamental difference from research activities conducted by various existing research institutes such as research centers and engineering laboratories in colleges and universities. Compared with traditional industry-universityresearch cooperation and various research institutions, collaborative innovation of colleges and universities has the basic characteristics of originality, collaboration and task-orientation [1].

\section{DILEMMAS OF LOCAL COLLEGES AND UNIVERSITIES FACED IN PROMOTION OF SCIENTIFIC AND TECHNOLOGICAL INNOVATION} AND SERVICE ABILITY

\section{A. Promotion of innovation and service ability of local colleges and universities is restricted because of deficiency in benefit drivers}

For a long time, the profit distribution mechanism efficiently motivating the innovation and service initiative of teachers has not been established well yet. As a result, inner cognitive bias of local colleges and universities on scientific and technological innovation and region-oriented service gave rise to the deficiency of innovation and service initiative among teachers. For example, teachers or even some leaders from local colleges and universities insist that the main task of teachers is teaching, and doing scientific research and service absolutely means "not attending to their proper duties". These teachers who are engaged in scientific research and social service are considered to make no substantial contribution to the income increase of universities, and accordingly, the interest appeals in income distribution and professional title appraisal of these teachers are ignored. Then the 
discrimination of interest distribution arises eventually, which will restrict the initiative of these teachers and retard their internal driving power.

\section{B. Innovation and service ability of local colleges and universities confined owing to dispersion and low efficiency of innovation resources}

Apart from the "985, 211" universities and those administrated by the Ministry of Education, local colleges and universities have problems of dispersed scientific resources, insufficient investment, redundant construction and inefficient inves tment, causing a serious waste of limited resources and low output quality. What's more, there is deficiency in the support of national provincial innovation platforms and the guidance of technological innovation leaders. The limited innovation platforms and service platforms go their own way alone, with difficulty in coordination and inadequateness of ability development.

\section{Promotion of innovation and service ability of local colleges and universities impeded by setbacks of scientific management} system

There are a lot of disadvantages in science and technology management system for universities, especially for local colleges and universities. From the exterior, because of the deficiency in lateral complementarities between local colleges and universities and competent departments of industries, scientific institutions and enterprises, industry-university-research is done separately, and there are a plenty of laboratorial research achievements but less application achievements which industries are badly in need of. From the interior, disciplinary power and level of local colleges and universities are weak and low, basic and applied researches are not good enough to hand in. Meanwhile, social satisfaction is not very good.

\section{Promotion of innovation and service ability of local colleges and universities affected by ambiguous objective}

At present, most of the innovation teams from Chinese local colleges and universities are those in "workshop style". That is, without much effective communication and collaboration with other research teams, the leader is only in charge of his apprentices or a small team made up by his trusted followers; what's more, research orientations are dispersed and there are no collaborative major scientific and technological innovation goals. From the outside, universities, scientific research institutions, industries and enterprises are managed by different departments. Driven by departmental interests, different units have different development strategic goals. Therefore, the major scientific and technological innovation goal, established to collaboratively solve common and key problems related with the nation, regions and industries, can not be formulated, and it is not to mention service ability .

\section{COLLABORATIVE INNOVATION, BEST EFFECTIVE APPROACH FOR PROMOTION OF SCIENTIFIC AND TECHNOLOGICAL INNOVATION AND SER VICE ABILITY OF LOCAL COLLEGES AND UNIVERSITIES}

The promotion of scientific and technological innovation and service ability of local colleges and universities contributes to the innovation-oriented national construction and sustainable development of the economic society. How to promote the scientific and technological innovation and service ability of local colleges and universities has become the focus of the whole society and the research hotspot. According to two years' practice of establishing Hunan Provincial Collaborative Innovation Center for Field Weeds Control, we insist that collaborative innovation is the best effective approach for the promotion of scientific and technological innovation and service ability of local colleges and universities which are similar to Hunan University of Humanities, Science and Technology.

\section{A. Diversity and limitation of scientific resources demanding collaborative promotion of scientific and technological innovation and service ability of local colleges and universities}

Scientific and technological innovation of local colleges and universities aims at enhancing transfer ratio of scientific achievements and providing service for local socio-economic development. Hence, in order to develop applicable scientific innovating achievements, researches related with the scientific and technological innovation of local colleges and universities should be conducted in an appropriate natural resource environment, which demands that the scientific and technological innovation of local colleges and universities should be extensively cooperative with local research institutes, industries and enterprises; and then, the innovation and service ability of local colleges and universities can be improved effectively to the maximum extent.

\section{B. Specificity of scientific innovation and service for local colleges and universities demanding the collaborative promotion of scientific \&technological innovation and service ability}

In local colleges and universities, scientific and technological innovation and local service are mutually supported or closely connected with disciplinary construction, educational teaching and talents cultivation [2]. Teachers simultaneously undertake the responsibility of teaching, scientific research and service. Therefore, not only are teachers responsible for teaching tasks, but they should consolidate disciplinary construction and do researches. When it comes to energy distribution of teachers or the distribution of school resources, there may be contradiction among teaching, scientific researches and service, which reminds us that the 
communication and cooperation among each unit of colleges and universities should be strengthened, and the limited resources should be coordinated so as to promote scientific and technological innovation and service ability.

\section{SUGGESTION FOR PROMOTING COLLABORATIVE INNOVATION OF LOCAL COLLEGES AND UNIVERSITIES}

\section{A. Strengthening consciousness of collaborative innovation, and create an atmosphere beneficial to collaborative innovation}

Local colleges and universities should establish specialized agency responsible for negotiating and making decisions for important affairs, planning the overall development of collaborative innovation, and effectively combining innovation forces with superior resources from universities and the society, so as to reach a deep integration between universities and the society. In order to create an atmosphere beneficial to collaborative innovation, universities should focus on ways of resource allocation, personnel management, mode of talents cultivation, and examination and evaluation mechanism, explore and clear internal mechanism obstacles which restrict the promotion of innovation and service ability, and break through the system "barriers" among universities and scientific research institutions, local government, industries and enterprises.

\section{B. Building platforms for collaborative innovation, and promoting mutual communication}

Local colleges and universities should fully exploit discipline advantages, make a deep integration inside universities, between universities and universities, among universities and scientific research institutions, industries, enterprises and local government, establish collaborative innovation mode which is of various forms and applicable to different researches, and build a relatively independent collaborative innovation platform with talents cultivation and solutions to important issues integrated. Based on the building of collaborative innovation platform, collaborative parties need to communicate comprehensively and exchange ideas with each other to fully understand the goal, requirement and difficulty of each party, and then try to give partners a hand, eliminate disagreement and find out the optimal balance point.

\section{Exploring the collaborative innovation mechanism, and coordinating profit distribution}

Local colleges and universities should explore the interest-sharing mechanism for collaborative innovation, implement the principle of "benefit distribution based on contribution", and connect all parties to collaborative innovation with impartial interest distribution chain. The government, universities, scientific research institutions and enterprises should respect mutually, and the interest distribution should be coordinated. Authorities for each party, the belongingness of personnel, resources, achievements and intellectual property should be defined to reach open sharing and sustainable development. Besides, in order to guarantee continuous achievement delivery of the platform of collaborative innovation and boost the scientific and technological innovation and service in local areas, they should explore a long-term mechanism for collaborative innovation, fully release and stabilize the vitality of innovation elements such as talents, capital, information and technology.

\section{Adhering to demand guidance, and making symbolic achievements}

Integrating with the great demand of regional development, local colleges and universities should lay the view of collaborative innovation on significant issues of economic and social development to provide sustainable technical support for industrial restructuring and technical progress, drive industrial restructuring and the development of emerging industries, try to play a key role in regional innovation system and become an important position in national technology innovation system. At the same time, taking the advantages of talents, platforms and wide views in local areas, they can actively develop project cooperation and service to produce a batch of important and symbolic achievements.

\section{ACKNOWLEDGMENT}

This program was supported by Innovation Base for Postgraduates Cultivation of Hunan Province (2261602) and Research Project of Teaching Reform of Degree and Graduate Education in Hunan (JG2016B106).

\section{REFERENCES}

[1] K. Xu, "The connotation, features and operational mechanism of collaborative innovation of universities and colleges," Vocational and Technical Education, vol. 36, pp. 49-52, 2015.

[2] Y. Liu, G. Yu, F. Zhang, "Exploration on the Cultivation of Innovative Talents in Local Colleges and Universities from the Perspective of Collaborative Innovation," Journal of Zhongzhou University, vol.33, pp. 101-104, 2016. 